\title{
Ultrastructural injury to human spermatozoa after freezing and thawing
}

\author{
D. M. Woolley* and D. W. Richardson $\dagger$ \\ Department of Anatomy, Royal (Dick) School of Veterinary Studies, University of Edinburgh, \\ and $\dagger$ M.R.C. Unit of Reproductive Biology, Forrest Road, Edinburgh, U.K.
}

\begin{abstract}
Summary. The ultrastructure of human spermatozoa at various stages of the freezing and thawing process was studied. In addition to conventional fixations, a freezesubstitution method was used to examine spermatozoa before they were thawed. Dilution in a glycerol-egg yolk-citrate medium caused slight swelling of the acrosome. During slow freezing, when large ice crystals grow in the diluent, the sperm plasmalemma became tighter, the mitochondria had more angular profiles and there was a reduction in electron density of the acrosomal contents. After thawing, the apical segment of the acrosome usually became swollen and the mitochondria appeared rounded. We deduce that these ultrastructural changes occur either during or after the thawing procedure.
\end{abstract}

\section{Introduction}

After a survey of the literature, Richardson (1975) concluded that frozen-thawed human semen is $15-25 \%$ less fertile than fresh semen. Freezing and thawing causes a reduction in percentage motility (Beck \& Silverstein, 1975), a reduced ability to penetrate cervical mucus (Fjällbrant \& Ackerman, 1969; Ulstein, 1973), and a reduced survival time in the female tract (Behrman, 1971). There also seems to be an impairment of oxidative metabolism (Ackerman, 1968; Guérin \& Czyba, 1976). The reported changes in morphology include damage to mitochondria (Friberg \& Nilsson, 1971; Pedersen \& Lebech, 1971), to the acrosome (Pedersen \& Lebech, 1971; Schill \& Wolff, 1974) and to the sperm tails (Boström \& Rubin, 1973).

The freezing process consists of incubation in the cryoprotective diluent, cooling, freezing, storage at low temperature and thawing, and the present work was an attempt to determine at which of these stages the structural damage to the spermatozoa occurs.

\section{Materials and Methods}

Conventional fixation was used to examine spermatozoa before dilution in the cryoprotectant, after dilution but before cooling, and after thawing. The technique of freeze-substitution fixation (Pease, 1967; Woolley, 1974) was used to study spermatozoa which had been frozen (slowly or by sudden quenching) but not thawed.

The comparisons of raw, diluted, frozen-substituted and frozen-thawed spermatozoa were performed on 5 ejaculates, one from each of 5 men. One further ejaculate from each of 2 of these donors was used for the comparison of slow and rapid freezing. The donors had sperm counts which fell within normal limits but were not of proven fertility.

After liquefaction of the semen at $35^{\circ} \mathrm{C}$ the motility of the spermatozoa was assessed by one of us (D.W.R.): the percentage of cells with progressive motility was estimated at $\times 250$ magnification by using a graticule as a counting aid.

The cryoprotective medium was composed of egg yolk $(20 \mathrm{ml})$, glycerol $(15 \mathrm{ml})$ and $65 \mathrm{ml}$ of an aqueous diluent containing $0.06 \mathrm{M}$-sodium citrate, $0.07 \mathrm{M}$-glucose, $0.07 \mathrm{M}$-fructose, $0.13 \mathrm{M}$-glycine, 600 units penicillin $/ \mathrm{ml}$ and $0.3 \mathrm{mg}$ streptomycin $/ \mathrm{ml}$ (Richardson, 1976). The semen, while being gently stirred, was diluted with an equal volume of diluent, added in four aliquots over a 2-min period.

* Present address: Department of Physiology, The Medical School, University Walk, Bristol, U.K. 
After equilibration $(2 \mathrm{~min})$, it was drawn into straws for routine freezing. These were sealed with spherical beads, placed in liquid nitrogen vapour for $15 \mathrm{~min}$ and then stored under liquid nitrogen. After $1 \mathrm{~h}$ some of the straws were removed and thawed in air at room temperature $\left(18-22^{\circ} \mathrm{C}\right)$ for $5 \mathrm{~min}$. One straw was incubated for a further $10 \mathrm{~min}$ at $35^{\circ} \mathrm{C}$ and its contents were used for estimating the post-thaw motility.

The samples of raw, diluted and frozen-thawed semen from any one ejaculate were prepared for electron microscopy. In three experiments 5 drops of the semen sample were put into $5 \mathrm{ml} 2.5 \%$ glutaraldehyde in $0.1 \mathrm{M}$-s-collidine buffer and left for $90 \mathrm{~min}$. In the other two experiments the fixative was modified to contain $4 \%$ glutaraldehyde, $4 \%$ sucrose and $0.12 \% \mathrm{CaCl}_{2}$ in $0.2 \mathrm{M}$-s-collidine (Pedersen, 1974). The spermatozoa were centrifuged from the fixative ( $1500 \mathrm{~g}$ for $15 \mathrm{~min}$ ) to form a loose pellet, which was rinsed in buffer for $15 \mathrm{~min}$, treated with collidine-buffered $1 \% \mathrm{OsO}_{4}$ for $60 \mathrm{~min}$, then dehydrated in a graded ethanol series, treated with propylene oxide and embedded in Epon 812.

For freeze-substitution, which involves dissolution of ice from tissues at low temperatures by an organic solvent (Rebhun, 1972; Pease, 1973), the diluted semen was placed as thick films on silver foil supports (Pl. 2, Fig. 5). Each piece of silver foil $(6 \times 20 \mathrm{~mm})$ was held in a cleft applicator stick which acted as a handle. For slow freezing these were suspended in liquid nitrogen vapour for $15 \mathrm{~min}$, then put under liquid nitrogen. In each experiment, one of these samples was thawed in air at this stage and its post-thaw motility determined. For rapid freezing, samples were quenched in Freon-22, at its freezing point $\left(-146\right.$ to $\left.-147^{\circ} \mathrm{C}\right)$ then transferred to liquid nitrogen before being immersed in the substituting fluid.

\section{EXPLANATION OF PLATES}

\section{PLATE 1}

Fig. 1. Acrosome from a control, untreated spermatozoon fixed in $2.5 \%$ glutaraldehyde. as = apical segment of acrosome; es = equatorial segment of acrosome; $n=$ nucleus; ne = nuclear envelope; im = inner acrosomal membrane; om = outer acrosomal membrane; $\mathrm{p}=$ plasmalemma. $\times 76500$.

Fig. 2. Acrosome from semen diluted in glycerol-egg yolk-citrate and equilibrated at room temperature for $2 \mathrm{~min}$ before fixation in $2.5 \%$ glutaraldehyde. The slight ruffling of the outer acrosomal membrane and swelling of the acrosome were more frequently seen after this treatment. $\times 76500$.

Fig. 3. Longitudinal section of part of the middle piece from an untreated, control spermatozoon. The fixative was $4 \%$ glutaraldehyde in a buffer containing $4 \%$ sucrose. The mitochondria are ovoid profiles lying against the dense fibres of the axonemal complex. $\mathrm{c}=$ mitochondrial crista; $\mathrm{m}=$ intercristal matrix; $\mathrm{df}=$ dense fibre. $\times 64500$.

Fig. 4. A section, comparable to that in Fig. 3, of a spermatozoon suspended in the cryoprotectant before fixation in $4 \%$ glutaraldehyde $+4 \%$ sucrose. No difference in mitochondrial structure is noticeable. $\times 64500$.

\section{PLATE 2}

Fig. 5. A frozen-substituted preparation after embedding. The sperm film, darkened by osmication, is seen adhering to the piece of silver foil, which is held in an applicator stick. After freezing, substitution-fixation, warming, removal of the substituting solvent, and dehydration, the entire preparation has been embedded in a polyethylene test tube of Epon 812 , then cut free. $\times 1$.

Fig. 6. An electron micrograph of the frozen-substituted cryoprotective diluent. The spaces in the reticular pattern are believed to indicate the former presence of ice crystals; the dark material around the spaces is presumed to consist of yolk globules. $\times 10000$.

Fig. 7. A frozen-substituted human spermatozoon showing the 'good' morphology characteristic of this mode of fixation. The intranuclear vacuole seen here is a normal structure. $\times 31500$.

Fig. 8. Part of the head of a frozen-substituted spermatozoon. The plasmalemma is very close to the underlying structures. The acrosome has a normal shape and appearance except that the contents of its apical segment are less electron dense than after conventional fixation. This reduced density is probably not simply an extraction effect due to the glutaraldehyde-ethylene glycol substitution fluid used as the fixative (see Fig. 9). $\times 78000$.

Fig. 9. An unfrozen spermatozoon fixed in the glutaraldehyde-ethylene glycol substitution fluid at room temperature; the acrosomal contents exhibit their usual electron density. $\times 78000$. 
PLATE
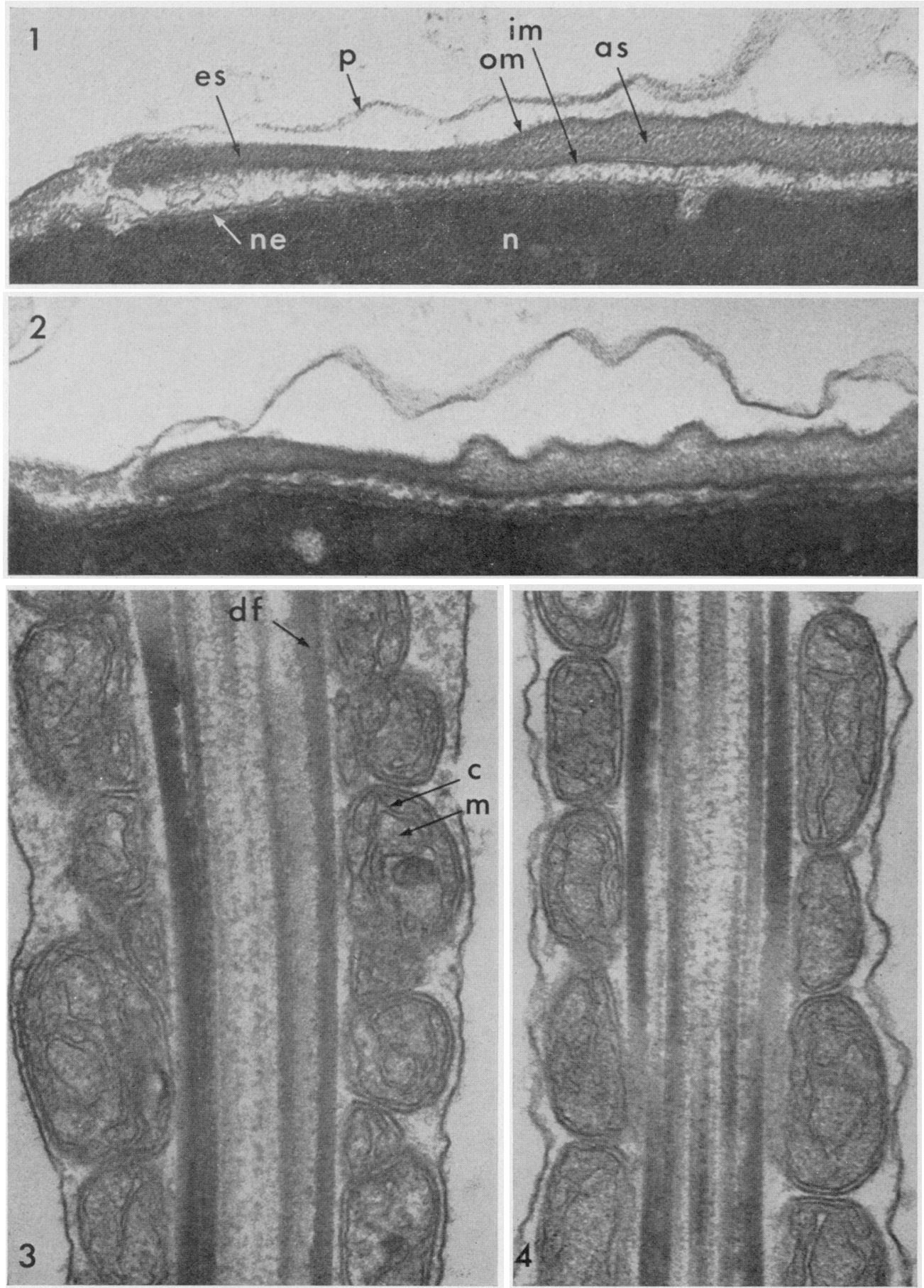

(Facing p. 390) 
PLATE 2

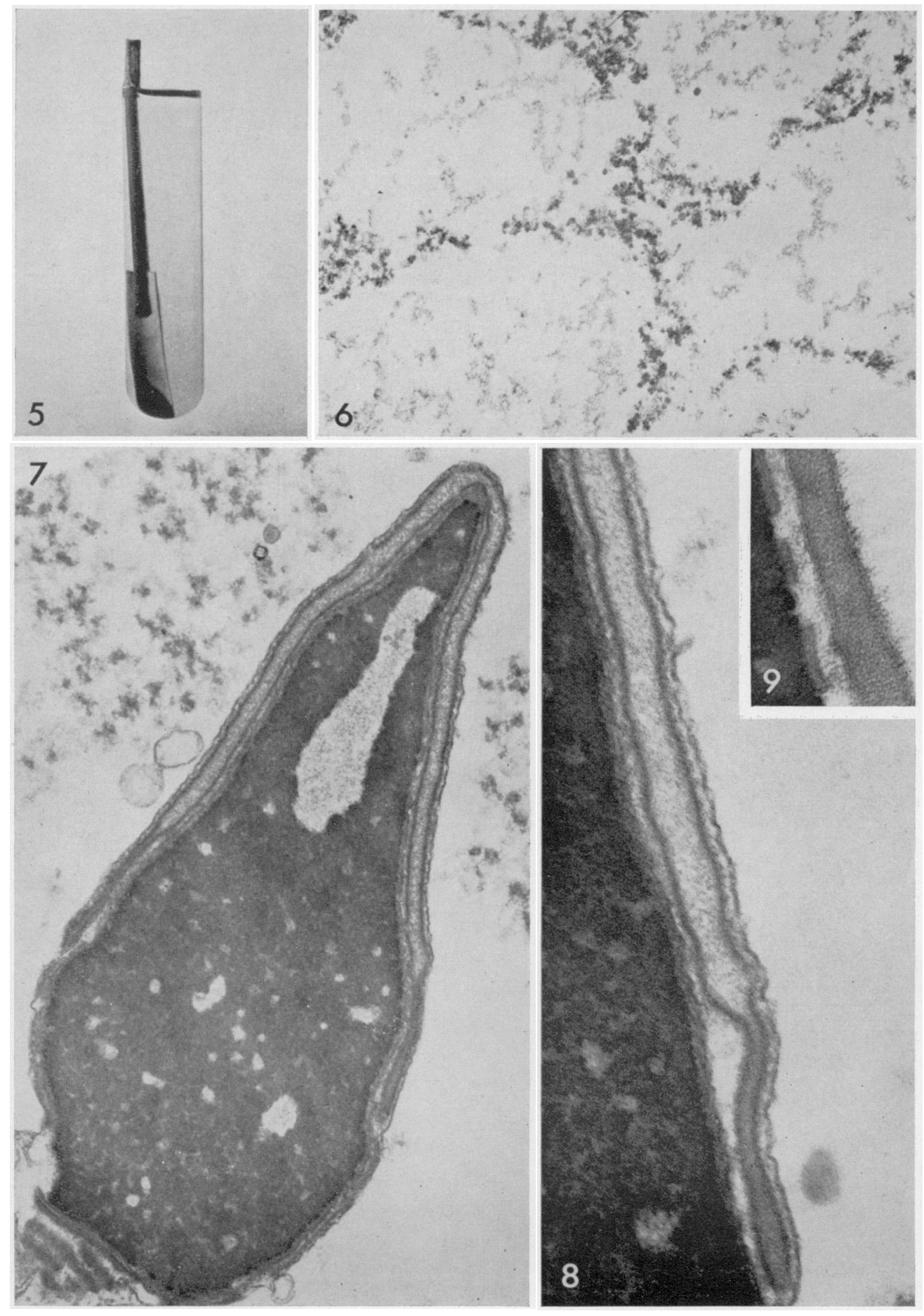


PLATE 3

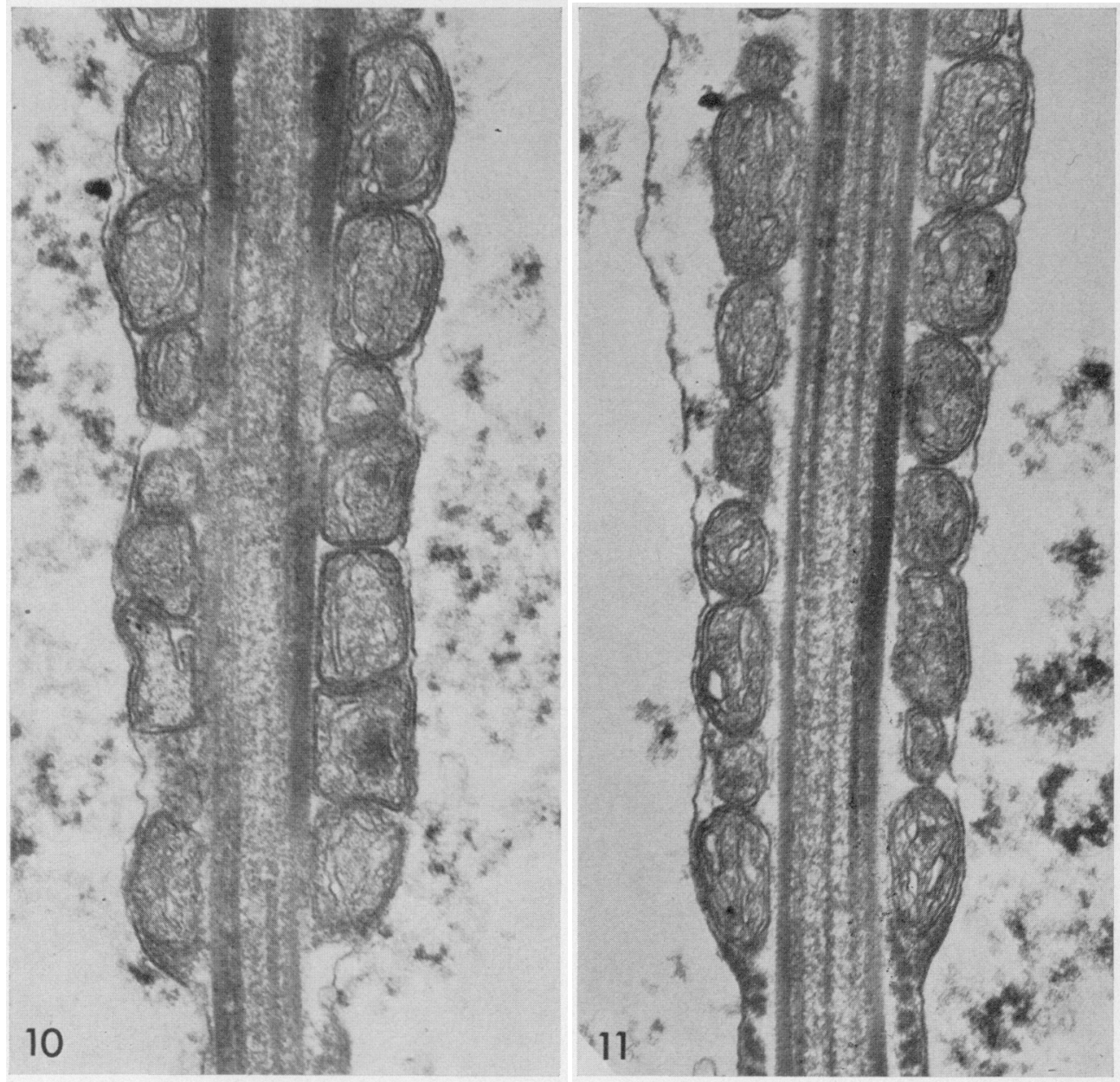

12

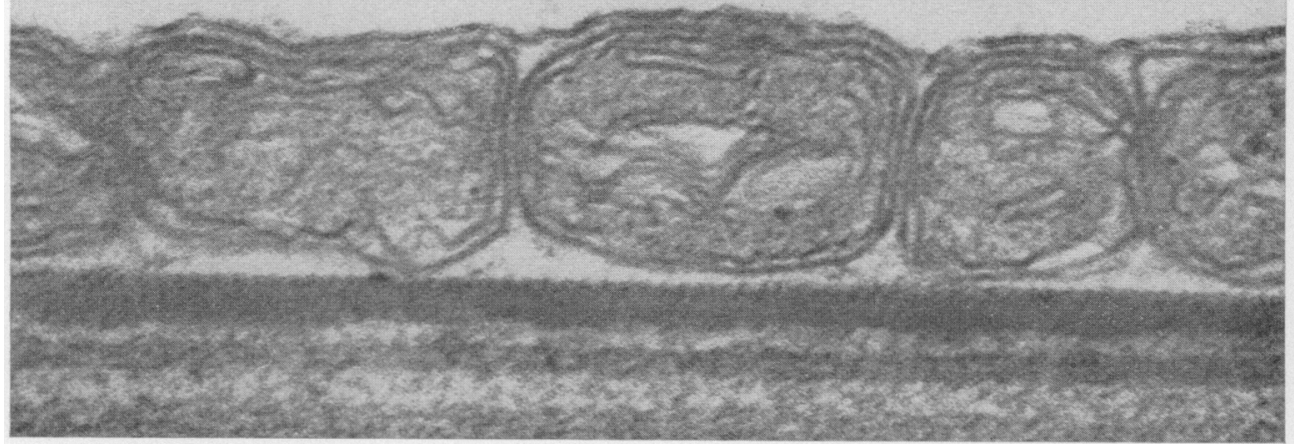


PLATE 4
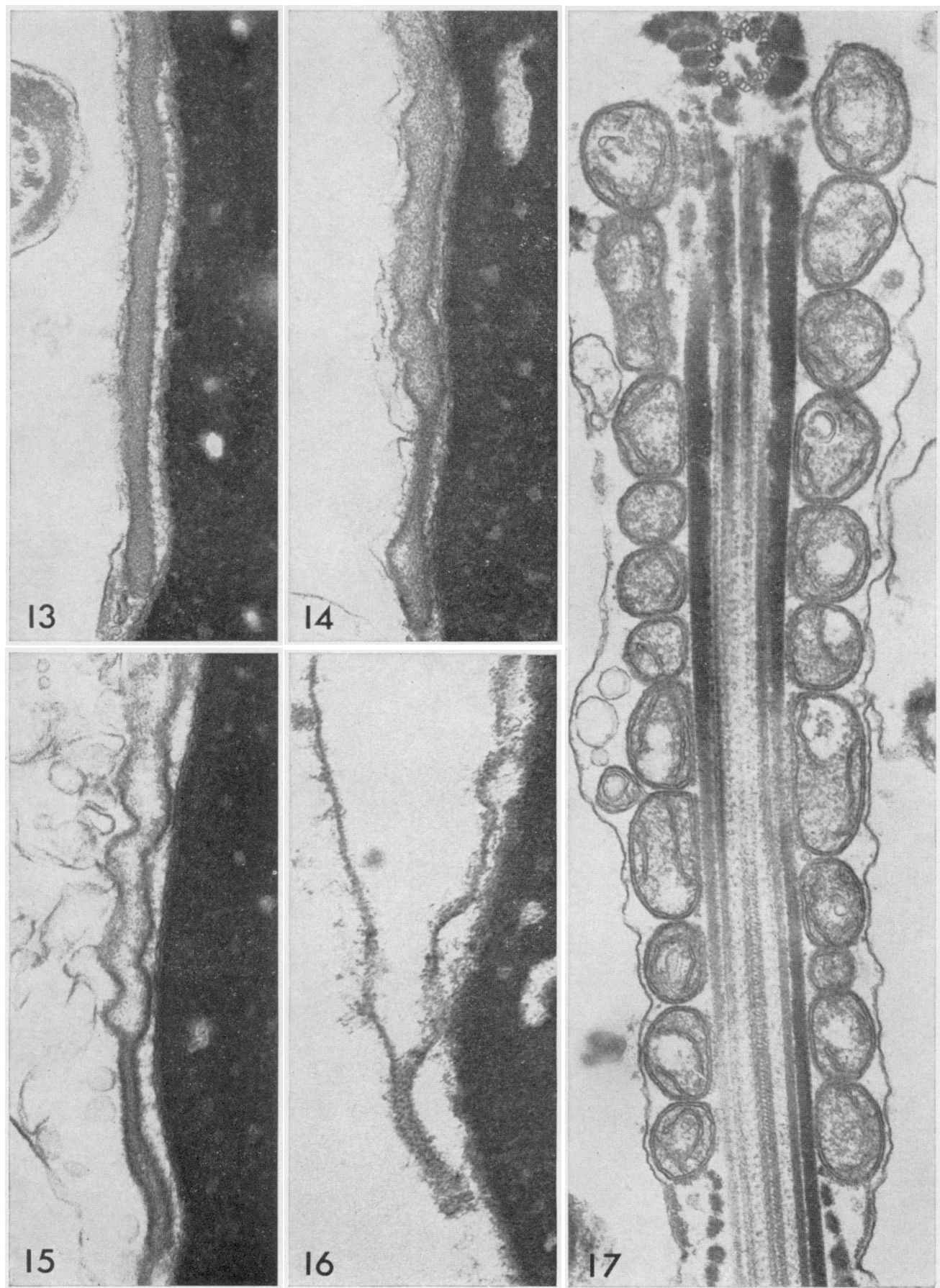
The substituting fluid, or ice solvent, was an ethylene glycol-water mixture containing glutaralde-

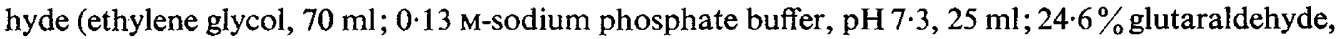
$5 \mathrm{ml}$ ). This fluid was prepared in $100 \mathrm{ml}$ quantities, put into screw-capped glass tubes and cooled to $-50^{\circ} \mathrm{C}$. The frozen sperm films were quickly transferred to this fluid and the tubes were kept at $-50 \pm 2{ }^{\circ} \mathrm{C}$ until the opacity of the films cleared $(30-40 \mathrm{~h})$, indicating that substitution was complete. Over the next $24 \mathrm{~h}$, the preparations were allowed to warm to room temperature. From experiments with gelatin models (Woolley, 1974) it is known that glutaraldehyde acts as a fixative in ethylene glycol at temperatures at least as low as $-20^{\circ} \mathrm{C}$. After freeze-substitution, the specimens were treated successively with three changes of phosphate buffer to remove the ethylene glycol, then placed in $1 \% \mathrm{OsO}_{4}$ in phosphate buffer for $10 \mathrm{~min}$. Dehydration through an ethanol series was followed by gradual infiltration with epoxy-propylene oxide mixtures. Finally the entire silver support with its attached films of spermatozoa was embedded in Epon 812 (Pl. 2, Fig. 5). Pieces of the block were cut with a jeweller's saw and the plastic containing the sperm film was easily removed from the silver support. Thin sections were cut with a diamond knife in the plane of the sperm film.

Thin sections of spermatozoa from all the treatments were stained with uranyl acetate and lead citrate and examined in an A.E.I. 6B electron microscope. The great morphological variety in any population of human spermatozoa makes it difficult to define the normal or unaffected structure and as a standard of normality we have used the morphology illustrated by Pedersen (1974). Ideally, in comparing the effects of different treatments, a quantitative analysis of the entire morphological spectrum would serve best, but since this was impracticable we have deliberately biased the selection of cells in favour of those most resembling normality. The deviations from normality, therefore, represent minimal degrees of change.

\section{Results}

The mean initial motility in the five ejaculates was $62 \cdot 6 \pm 3 \cdot 4 \%$ (s.e.m.). The effect of freezing and thawing on motility is expressed as the 'recovery', i.e. the percentage of the initial motility which is recovered after thawing. For the samples frozen and thawed in straws the mean recovery was $63 \cdot 7 \pm$

\section{PLATE 3}

Fig. 10. A middle piece from a slowly frozen, substitution-fixed spermatozoon. The plasmalemma is closely apposed to the mitochondria, which have angular profiles and appear to be tightly packed. $\times 37000$.

Fig. 11. A middle piece from a quench-frozen, substitution-fixed spermatozoon. Although not markedly different from that in Fig. 10, the mitochondria are less angular in profile and the plasmalemma seems to be less tightly apposed. The morphology is generally similar to that seen in unfrozen, conventionally fixed cells (compare with Pl. 1, Figs 3 and 4). $\times 37000$.

Fig. 12. Part of the middle piece of a slowly frozen, substitution-fixed spermatozoon, to show the mitochondrial morphology in more detail. There are many irregular cristae, in places dilated, within a homogeneously dense matrix (see also Fig. 10). $\times 92000$.

\section{PLATE 4}

Figs 13-16. Acrosomes from frozen-thawed spermatozoa fixed in $2.5 \%$ glutaraldehyde, for comparison with those in Figs 1 and 2, and Figs 7 and 8. After freezing and thawing the spermatozoa, it was possible to find unaffected acrosomes (Fig. 13), although most showed some surface irregularity and distension of the apical segment (Fig. 14), and many were severely swollen and appeared to have lost some of their content (Figs 15 and 16). The apical plasmalemma over such affected acrosomes was usually swollen or disrupted. $\times 48000$.

Fig. 17. An entire middle piece from a frozen-thawed spermatozoon fixed in $4 \%$ glutaraldehyde $+4 \%$ sucrose. The visible changes in this part of the cell are confined to the mitochondria (see Pl. 3, Fig. 10), the other structures of the neck and tail are normal in appearance. The mitochondria appear rounded and contain cristae of uniform width. The intercristal matrix is no longer homogeneous (compare with Pl. 1, Figs 3 and 4) but contains electron-translucent spaces. $\times 37500$. 
$2.9 \%$. Spermatozoa frozen on the silver foils before freeze-substitution must have experienced similar cooling rates because the recovery in parallel samples which were thawed was similar $(65 \cdot 1 \pm$ $5.4 \%$.

The morphological observations are presented for each step of the freeze-thawing procedure.

Before dilution. These samples showed the pleomorphism characteristic of human sperm populations and contained many apparently malformed cells, including those displaying all degrees of what is considered acrosomal damage. However, many of the acrosomes could be classed as normal: their internal structure appeared moderately electron dense and homogeneous except for a fine granularity (PI. 1, Fig. 1). The mitochondrial morphology varied with the fixative used, and we considered the structure after using Pedersen's (1974) fixative to be 'normal' (see 'Discussion'). Such mitochondria had bluntly angular profiles, their cristae were numerous, irregularly arranged and in places swollen; and the intercristal matrix was moderately electron dense and homogeneous (PI. 1, Fig. 3). The plasmalemma was frequently swollen or broken, especially after the use of the sucrose-free fixative. Its looseness or tightness, therefore, could not be determined from conventionally fixed spermatozoa.

After dilution. The morphology of the acrosome seemed to have been changed by exposure to the diluent, although not markedly. The apical segment was very slightly swollen, the outer acrosomal membrane often appeared slightly ruffled and the acrosomal content was less homogeneous (P1. 1, Fig. 2). No change was detected in the structure of the mitochondria (Pl. 1, Fig. 4).

After freezing. The spermatozoa showed good morphological preservation after freeze-substitution. The profile of the acrosome was normal (Pl. 2, Fig. 7), and its content, although less electron dense, retained its typical even granularity (Pl. 2, Fig. 8). The mitochondria were unchanged except that they appeared more closely packed and thus more angular in profile (Pl. 3, Figs 10 and 12). The cell membrane was usually undamaged and closely apposed to the underlying organelles (PI. 2, Figs 7 and 8 ; Pl. 3, Figs 10 and 12). In quench-frozen spermatozoa the plasmalemma over the middle piece was less tight and the mitochondria were not compressed (Pl. 3, Fig. 11).

After thawing. In thawed samples there was a prevalence of spermatozoa with swollen acrosomes. The least severe change resembled that seen after dilution--a ruffling of the outer acrosomal membrane and an increased heterogeneity of the acrosomal contents (PI. 4, Fig. 14). Many acrosomes were more severely swollen and distorted and appeared to have lost much of their content (Pl. 4, Figs 15 and 16). These changes were limited to the apical segment; the equatorial segment was unaffected. The incidence of acrosome damage was greater in some ejaculates than others, but in all 5 ejaculates it was possible to find some acrosomes of normal appearance. When the sucrose-containing fixative was used, the mitochondrial morphology in thawed cells was distinctly different from that seen in the unfrozen samples of the same ejaculates: the mitochondria had rounder profiles, their cristae were more plate-like, with little swelling of the intracristal spaces, and the intercristal matrix had become heterogeneous (Pl. 4, Fig. 17).

\section{Discussion}

The new findings in this paper are those based on the freeze-substitution technique, which we believe to be a way of revealing the morphology of cells in the frozen state. This belief is considered justified because it has been shown that (i) ice does dissolve in the solvent, coincidentally with a loss of opacity in the specimen and (ii) glutaraldehyde does act as a fixative in ethylene glycol, at least at temperatures down to $-20^{\circ} \mathrm{C}$ (Woolley, 1974). The temperature at which chemical fixation begins is important. If fixation did not occur until much higher temperatures were reached, cytoplasmic movements might occur after the substitution of the ice and so obliterate aspects, e.g. the pattern of ice crystals, of the frozen state morphology. There are two indications that such a re-constitution of the specimens did not occur. One is that a reticular pattern of yolk globules, suggestive of large intervening ice crystals, was seen in the diluent after substitution fixation (Pl. 2, Fig. 6). The second indication comes from our (unpublished) finding that exposure of spermatozoa to $70 \%$ ethylene glycol before adding glutaraldehyde causes extreme disruption of the acrosome. Therefore, during substitution at $-50^{\circ} \mathrm{C}$, chemical fixation probably occurs while the solvent penetrates the specimen. 
Even so, it might have been expected that at $-50^{\circ} \mathrm{C}$ the frozen cells would suffer structural damage from the re-growth of ice crystals. There was, however, no sign of this 're-crystallization' in the sections. The morphology of the spermatozoa was consistent with their known potential viability. The substitution temperature must therefore be sufficiently low to prevent the growth of ice crystals, as found by Bank (1973) who re-warmed yeast cells after rapid cooling and observed that "the rate of crystal growth is so slow at $-50^{\circ} \mathrm{C}$ that even after $24 \mathrm{hr} \ldots$ the crystals were not of sufficient size to be positively identified". After slower cooling the yeast cells could be warmed to even higher temperatures without structural alteration.

We agree with Pedersen \& Lebech (1971) and Schill \& Wolff (1974) that the sperm organelles obviously altered by freezing and thawing are the acrosome and the mitochondria. Samples prepared by freeze-substitution, however, do not show these ultrastructural changes, and so these changes occur either during or shortly after thawing. It is possible that some aspect of the thawing process, perhaps the rate of ice crystal growth, might be causing the intracellular damage. A faster thawing method might give better survival. But the frozen spermatozoa, while not grossly damaged, may nevertheless have suffered subtle changes during cooling or freezing. Events not detectable by microscopy may have predetermined further changes which followed when the cells were thawed and their activity resumed. One such subtle change, which we cannot interpret, is the change in electron density of the acrosomal content in the 'frozen' spermatozoa: this is not a trivial effect of the substituting solvent (compare Pl. 2, Figs 8 and 9). One possible change might have been an abstraction of water from the cells during the freezing of the diluent. According to the 'salt injury' theory of Lovelock (1953), the intracellular solute concentration would be expected to rise during the freezing of the diluent; then as the cells are suddenly exposed to the lower tonicity of the melting diluent during thawing, they are damaged by osmotic swelling. This theory, which was proposed to explain the post-thaw haemolysis of erythrocytes, has been challenged (review by Lozina-Lozinskii, 1974) but it is mentioned here in relation to human spermatozoa because the tight membranes and 'compressed' mitochondria of the frozen-substituted cells are suggestive of dehydration and because the subsequent injuries to the cells appear as swellings of the membrane-bound organelles.

Most frozen-thawed spermatozoa had some degree of acrosomal swelling. Frequently the outer acrosomal membrane and some of the contents were lost, but such severe damage is hard to reconcile with the failure of Ackerman (1970) to detect a liberation of hyaluronidase, and membrane breakage may therefore be a fixation-induced change. A swelling of the mitochondria is less certainly established, although they were more rounded in profile and there were electron-lucent spaces in the intercristal matrix. These two effects, while giving the impression of an increased mitochondrial volume, need to be supported by a stereological analysis. There is, however, another reason for thinking that the damage to frozen-thawed mitochondria might be an osmotic effect. Similarly 'damaged' spermatozoa can be obtained by using a lower osmotic strength fixative for fresh cells (see 'Methods'). When low concentrations of glutaraldehyde or osmium tetroxide are used for primary fixation, the mitochondria generally seem to be large and rounded (Chrzanowski, 1966; Fujita, Miyoshi \& Tokunaga, 1970; Churg, Zaneveld \& Schumacher, 1974), but if the fixative contains sucrose, the mitochondria appear more flattened and angular, with irregularly dilated cristae (Novikoff, Cohen, Novikoff \& Davis, 1971; Pedersen, 1974), as they do after quench-freeze substitution (Pl. 3, Fig. 11). We therefore think that the mitochondria, in vivo, are more likely to be flattened and angular and that the rounded type of mitochondrion, and the other freeze-thaw damage, is probably due to osmotic swelling. If this suggestion is correct, it may be possible to prevent such osmotic damage by thawing very small aliquots of frozen semen rapidly in a hypertonic medium.

\section{References}

ACKerman, D.R. (1968) The effect of cooling and freezing on the aerobic and anaerobic lactic acid production of human semen. Fert. Steril. 19, 123-128.
ACKERMAN, D.R. (1970) Hyaluronidase in human semen and sperm suspensions subjected to temperature shock and to freezing. J. Reprod. Fert. 23, 521-523. 
BANK, H. (1973) Visualization of freezing damage. II. Structural alterations during warming. Cryobiology 10, 157-170.

Beck, W.W. \& Silverstein, I. (1975) Variable motility recovery of spermatozoa following freeze-preservation. Fert. Steril. 26, 863-867.

Behrman, S.J. (1971) Preservation of human sperm by liquid nitrogen vapour freezing. In Current Problems in Fertility, pp. 10-16. Eds A. Ingelman-Sundberg \& N.-O. Lunell. Plenum Press, New York.

Boström, K. \& RüBIN, S.-O. (1973) Destruction of spermatozoa in freeze-thawing of human semen. Scand.J. Urol. Nephrol. 7, 120-122.

Chrzanowski, S. (1966) Ultrastructure of human spermatozoon. Pol. med.J. 5, 482-491.

Churg, A., Zaneveld, L.J.D. \& Schumacher, G.F.B. (1974) Detergent treatment of human and rabbit spermatozoa: ultrastructural changes and release of midpiece enzymes. Biol. Reprod. 10, 429-437.

FJällbrant, B. \& ACKerman, D.R. (1969) Cervical mucus penetration in vitro by fresh and frozen preserved human semen specimens. J. Reprod. Fert. 20, 515-517.

FriberG, J. \& Nilsson, O. (1971) Motility and morphology of human sperms after freezing in liquid nitrogen. In Current Problems in Fertility, pp. 17-22. Eds A. Ingelman-Sundberg \& N.-O. Lunell. Plenum Press, New York.

Fujita, T., Miyoshi, M. \& Tokunaga, J. (1970) Scanning and transmission electron microscopy of human ejaculate spermatozoa with special reference to their abnormal forms. Z. Zellforsch. mikrosk. Anat. $105,483-497$.

Guerin, J.F. \& CzYBA, J.C. (1976) Modifications de la motilité et de l'activité respiratoire des spermatozoides humains après congélation dans l'azote liquide. C. r. Séanc. Soc. Biol. 170, 395-397.

LOVELOCK, J.E. (1953) The haemolysis of human red blood cells by freezing and thawing. Biochim. biophys. Acta 10, 414-426.

Lozina-LozinskiI, L.K. (1974) Studies in Cryobiology, Chap. VIII, pp. 186-194. John Wiley \& Sons, New York.
Novikoff, P.M., Cohen, J., Novikoff, A.B. \& Davis, C. (1971) Cytochemical visualization of the midpieces of ejaculated human spermatozoa. J. Microscopie 11, 169-174.

Pease, D.C. (1967) Eutectic ethylene glycol and pure propylene glycol as substituting media for the dehydration of frozen tissue. J. Ultrastruct. Res. 21, 75-97.

PeAse, D.C. (1973) Substitution techniques. In Advanced Techniques in Biological Electron Microscopy, pp. 35-66. Ed. J. K. Koehler. Springer-Verlag, Berlin.

Pedersen, H. (1974) The human spermatozoon. Thesis, Aarhus University, Denmark.

Pedersen, H. \& Lebech, P.E. (1971) Ultrastructural changes in the human spermatozoon after freezing for artificial insemination. Fert. Steril. 22, 125-133.

Rebhun, L.I. (1972) Freeze-substitution and freezedrying. In Principles and Techniques of Electron Microscopy. Biological Applications, Vol. 2, pp. 3-49. Ed. M. A. Hayat. Van Nostrand Reinhold Co., New York.

Richardson, D.W. (1975) Artificial insemination in the human. In Modern Trends in Human Genetics, Vol. 2, pp. 404-448. Ed. A. E. H. Emery. Butterworth, London.

RichaRDSON, D.W. (1976) Techniques of sperm storage. In Artificial Insemination, pp. 97-129. Eds J. M. Brudenell, A. McLaren, R. V. Short \& E. M. Symonds. Royal College of Obstetricians and Gynaecologists, London.

SchilL, W.-B. \& WoLfF, H.H. (1974) Ultrastructure of human sperm acrosome and determination of acrosin activity under conditions of semen preservation. Int. J. Fert. 19, 217-223.

ULSTEIN, M. (1973) Fertility, motility and penetration in cervical mucus of freeze-preserved human spermatozoa. Acta obstet. gynaec. scand. 52, 205-210.

WoOLLeY, D.M. (1974) Freeze-substitution: a method for the rapid arrest and chemical fixation of spermatozoa. J. Microscopy 101, 245-260.

Received 4 January 1978 